\title{
THE
}

\section{Properties of Rossby Waves in the North Atlantic Estimated from Satellite Data}

Vladimir Osychny

University of Rhode Island

Peter C. Cornillon

University of Rhode Island, pcornillon@uri.edu

Follow this and additional works at: https://digitalcommons.uri.edu/gsofacpubs

\section{Citation/Publisher Attribution}

Osychny, V., \& Cornillon, P. (2004). Properties of Rossby Waves in the North Atlantic Estimated from Satellite Data. J. Phys. Oceanogr., 34, 61-76. doi: 10.1175/1520-0485(2004)034<0061:PORWIT>2.0.C0;2 Available at: https://doi.org/10.1175/1520-0485(2004)034<0061:PORWIT>2.0.C0;2

This Article is brought to you for free and open access by the Graduate School of Oceanography at DigitalCommons@URI. It has been accepted for inclusion in Graduate School of Oceanography Faculty Publications by an authorized administrator of DigitalCommons@URI. For more information, please contact digitalcommons-group@uri.edu. 


\title{
Properties of Rossby Waves in the North Atlantic Estimated from Satellite Data
}

\author{
Vladimir Osychny AND Peter CoRnillon \\ Graduate School of Oceanography, University of Rhode Island, Narragansett, Rhode Island
}

(Manuscript received 24 July 2002, in final form 2 July 2003)

\begin{abstract}
This study uses satellite observations of sea surface height (SSH) to detect westward-propagating anomalies, presumably baroclinic Rossby waves, in the North Atlantic and to estimate their period, wavelength, amplitude, and phase speed. Detection involved a nonlinear fit of the theoretical dispersion relation for Rossby waves to the time-longitude spectrum at a given latitude. Estimates of period, wavelength, and phase speed resulted directly from the detection process. Based on these, a filter was designed and applied to extract the Rossby wave signal from the data. This allowed a mapping of the spatial variability of the Rossby wave amplitude for the North Atlantic. Results showed the familiar larger speed of observed Rossby waves relative to that expected from theory, with the largest differences occurring at shorter periods. The data also show that the dominant Rossby waves, those with periods that are less than annual, propagated with almost uniform speed in the western part of the North Atlantic between $30^{\circ}$ and $40^{\circ} \mathrm{N}$. In agreement with previous studies, the amplitude of the Rossby wave field was higher in the western part of the North Atlantic than in the eastern part. This is often attributed to the influence of the Mid-Atlantic Ridge. By contrast, this study, through an analysis of the wave spatial structure, suggests that the source of the baroclinic Rossby waves at midlatitudes in the western North Atlantic is located southeast of the Grand Banks where the Gulf Stream and the deep western boundary current interact with the Newfoundland Ridge. The spatial structure of the waves in the eastern North Atlantic is consistent with the formation of these waves along the basin's eastern boundary.
\end{abstract}

\section{Introduction}

Rossby waves play an important role in the response of the ocean to forcing. In this paper we discuss properties of the sea surface height (SSH) anomaly field in the Rossby wave portion of the frequency-wavenumber spectrum of the Ocean Topography Experiment (TOPEX)/Poseidon data in the midlatitude North Atlantic Ocean. Our interest was initiated by, although not restricted to, an investigation of the impact of long baroclinic Rossby waves on the variability of the Gulf Stream path.

A number of studies have shown that westward-propagating anomalies (we refer to these as Rossby waves as has been done in previous papers on this subject as well as for brevity) can be detected in SSH data. Chelton and Schlax (1996, hereinafter CS) provided a global description of the Rossby wave field based on the 3-yr TOPEX/Poseidon time series available to them at the time. They concentrated on major features that appear to be common to such waves in all of the major ocean basins although most of their results were presented with examples from the North Pacific. Chelton and Schlax

Corresponding author address: Vladimir Osychny, Graduate School of Oceanography, University of Rhode Island, Narragansett, RI 02882-1197.

E-mail: vosychny@gso.uri.edu
(1996) observed Rossby waves with periods ranging from 6 to 24 months and wavelengths ranging from 500 $\mathrm{km}$ at $50^{\circ} \mathrm{N}$ to $10000 \mathrm{~km}$ or longer in the Tropics. They found these waves to propagate faster westward in midlatitudes than expected from simple linear theory. They also found the wave amplitude to be larger west of major topographic features than east of these features, which led them to suggest that topography may support the generation or amplification of the observed waves, although recently $\mathrm{Fu}$ and Chelton (2001) noted that this increase in the wave amplitude is observed often, but not always. Last, CS demonstrated that the spatial structure of the waves in the Tropics was consistent with $\beta$ refraction: wave crests/troughs extending over a range of latitudes tend to curve toward midlatitudes as they cross the basin because of an increase in the phase speed toward the equator. In contrast, outside the Tropics they found that the SSH anomalies lose their coherent structure in the north-south direction soon after generation.

Chelton and Schlax (1996) drew their conclusions by considering westward-propagating features, presumably Rossby waves, seen in time-longitude diagrams of SSH anomalies (see our examples in Fig. 1). In particular, they estimated the wave phase speed by fitting straight lines to propagating features in these diagrams. Zang and Wunsch (1999, hereinafter ZW) pointed out that CS's approach characterizes the propagation of anom- 
$45^{\circ} \mathrm{N}$

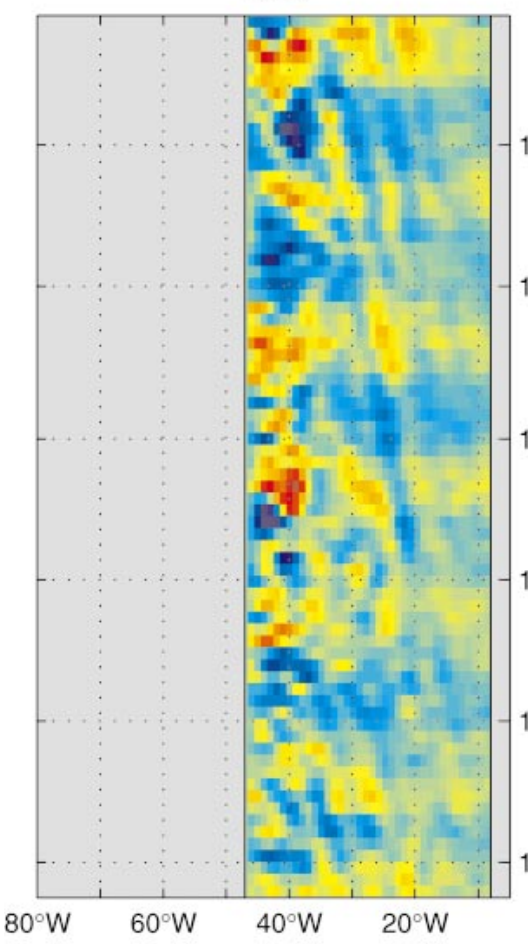

$35^{\circ} \mathrm{N}$

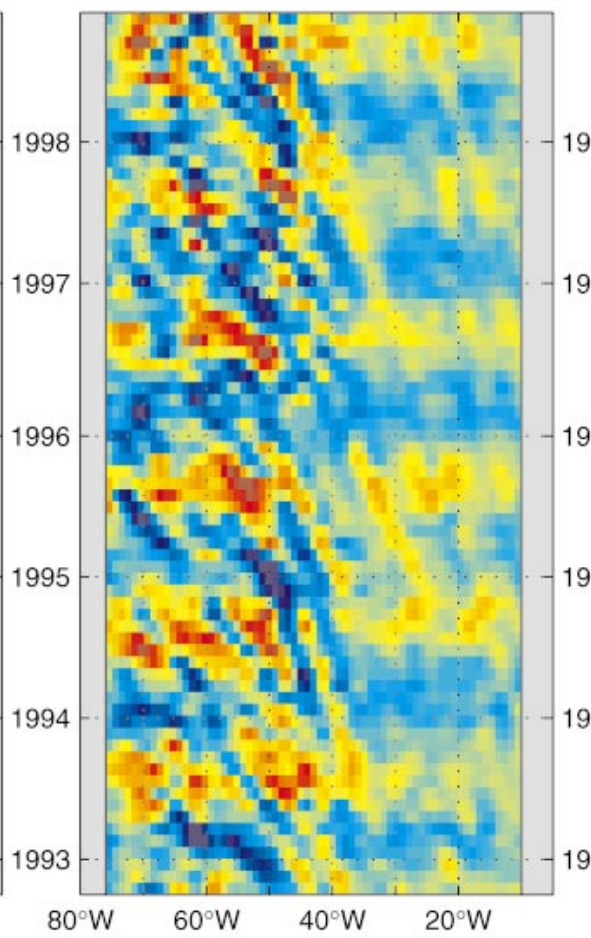

$25^{\circ} \mathrm{N}$

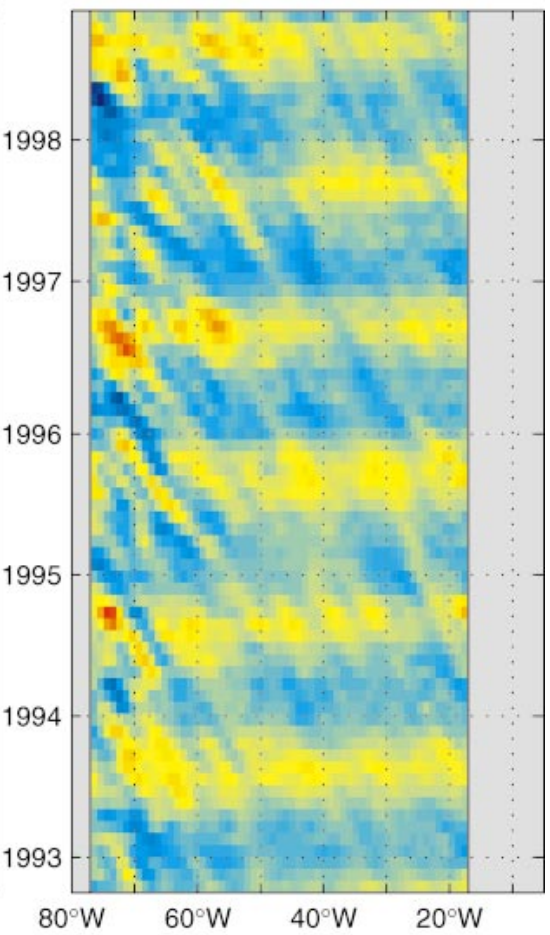

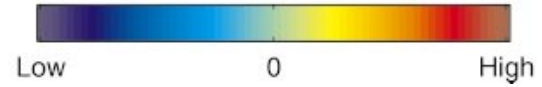

FIG. 1. Time-longitude diagrams of the SSH anomalies. Color scale is the same for all plots in the figure.

alies as a whole; it does not discriminate between constituents of wave packets-Rossby waves of different wavenumbers and frequencies.

In a spectral analysis of the wave field, one that did discriminate between wave constituents, Zang and Wunsch (1999) found that outside the Tropics 1) a substantial fraction of energy was consistent with the classical theory (mostly, at large spatial and temporal scales) and 2) short Rossby waves were faster than predicted by the theory and, thus, responsible for the speed up observed by CS. Zang and Wunsch's conclusions contradicted those of CS by stressing that the fraction of the total energy consistent with the classical theory was substantial.

Like ZW we use a spectral approach to detect Rossby waves and estimate their parameters although details of our data processing differ from that of ZW in several crucial ways. They employed a beamforming technique, that is, a high-resolution method of spectral estimation. These methods rely on a priori assumptions about the signal structure. Most important, the methods detect the waves on a rather widely spaced grid of frequencies. At these frequencies the signal is assumed to consist of a single sinusoid buried in noise. As a result, all of the estimates (including those of uncertainties) are contingent on the validity of these assumptions. Instead, we resort to classical (Fourier) spectral estimation. Its properties are well known, and the basic assumptions are not that strict; hence we sacrifice somewhat higher wavenumber resolution for a denser frequency grid, a more complicated signal composition in wavenumber, and the better understood Fourier analysis. In addition to serving our goals, classical spectra can be used to address the validity of the assumptions used by ZW.

We begin by considering the spectral composition of the Rossby wave field, characterizing the period, wavelength, and phase speed of the observed waves. Then, we describe the spatial pattern of the wave field, addressing the following questions: Where are the waves generated? Do they have any coherent structure? If they do, how does that structure change as the waves propagate westward and especially as they cross the MidAtlantic Ridge? Do they show a significant increase in amplitude because of interaction with the Mid-Atlantic Ridge? Last, where and why is the wave field most energetic?

\section{Data and methods}

This study uses a subset of the TOPEX/Poseidon SSH anomaly dataset provided by Van Snyder and Zlotnicki (2000). Briefly, they applied all standard corrections to 
the raw TOPEX/Poseidon measurements, subtracted a modeled tidal signal and an estimated mean sea surface, interpolated data onto a uniform $1^{\circ} \times 1^{\circ} \times 5$ day grid, and subtracted the temporal mean field at each grid point. The subset of data that we use spans the period from December 1992 to December 1998 and covers the North Atlantic from the equator to $60^{\circ} \mathrm{N}$. The conclusions presented here relate to the region between $15^{\circ}$ and $47^{\circ} \mathrm{N}$ where our procedure provides confident detection of Rossby waves.

We begin by low-pass filtering the data in time in accordance with the large temporal and spatial scales of interest and subsampling the resulting smoothed fields with a time step of $\Delta t=29.7$ days, three repeat TOPEX/Poseidon cycles. The filtering was performed with an eighth-order Chebyshev infinite impulse response filter (Jackson 1996) with the transition band between six (the Nyquist period for the new time step) and seven repeat TOPEX/Poseidon cycles. The residual temporal mean values and linear trends were subtracted from the filtered, subsampled fields to obtain the associated anomaly field for further analysis.

Detection of Rossby waves and estimation of their parameters was performed using time-longitude diagrams of data at a given latitude. (Examples are shown in Fig. 1.) Two-dimensional spectra were estimated for the diagrams. Similar to the previous studies, Rossby waves were identified by energy peaks in the part of the spectrum that represents westward propagation. Evident in Fig. 1 is the large, predominantly annual, basinwide signal that is mainly steric in nature. Since the focus of this work is on propagating anomalies, we remove this basin-scale signal to facilitate subsequent analysis. This was done by subtracting the best fit straight line in longitude at each degree of latitude for each 29.7-day field. Certainly a linear trend only approximates a more complicated spatial structure of the annual signal. However, the goal here is to unmask the propagating anomalies and to use the subsequent analysis based on two-dimensional spectra to obtain further refinements.

Estimation of the spectra began with a time-longitude periodogram computed at each latitude. This was obtained via the fast Fourier transform of the data smoothed by a two-dimensional Chebyshev window (Emery and Thomson 1998) to suppress possible sidelobes. The size of the window was determined from the number of longitudinal data values at a given latitude and from the length of the time series. Periodograms corresponding to three adjacent latitudes were averaged and the resulting estimate was assigned to the central latitude. Averaging improved statistical reliability of the spectral estimates. Additional smoothing was performed in the frequency-wavenumber domain with a three frequency by three wavenumber moving average. Examples of the spectra are shown in Figs. 2 and 3.

To determine the possible effect of nonstationarity, spectra were computed for the entire time series and for 3-yr-long overlapping subsections. The spectra of the subsections were not significantly different from one another or when compared with the spectrum of the entire time series. Therefore we concluded that the time series was, to the accuracy of our estimates, temporally stationary over the analyzed interval.

On the other hand, inspection of the time-longitude diagrams (Fig. 1) reveals a noticeable variation in the amplitude of anomalies and, even more important, in their speed of propagation between the eastern and the western part of the North Atlantic. This is seen most clearly in the region between $25^{\circ}$ and $40^{\circ} \mathrm{N}$ where a large change takes place in the anomaly field over a relatively narrow zone approximately in the middle of the North Atlantic (see the time-longitude diagram for $35^{\circ} \mathrm{N}$, Fig. 1). Fortunately, the ocean at these latitudes is sufficiently wide to allow us to estimate spectra using data covering two nonoverlapping subsections representing the western and the eastern basins as well as the entire width of the basin.

The two-dimensional spectra, whether they be for the width of the basin (Figs. 2 and 3) or for the eastern or the western basins (not shown), provide a basis for evaluating the phase speed of the observed Rossby waves. The speed can be estimated by locating frequencies and wavenumbers of individual peaks in the spectra (as in ZW). The uncertainty of such a speed estimate depends on the uncertainty of a given spectral peak and on the resolution of the spectrum. Averaging over appropriate regions in frequency-wavenumber space can improve this uncertainty in speed estimation. However, the regions over which the averages are performed must be properly chosen. Here our choice is motivated by three observations. First, Figs. 2 and 3 show that at many latitudes, especially in the $20^{\circ}-35^{\circ} \mathrm{N}$ range, spectral peaks form a more or less continuous ridge of elevated energy, presumably revealing a form of an empirical dispersion relationship. Second, although we do not know the mathematical form of the dispersion relationship, CS, ZW, and Fu and Chelton (2001) conclude that the standard theory does describe a significant portion (at least $50 \%$ ) of the dynamics of observed westward propagating anomalies. The standard theory is defined by the following dispersion relation:

$$
\omega=\frac{-\beta k}{k^{2}+l^{2}+\left(1 / R_{d}^{2}\right)},
$$

where $\omega$ is the frequency of the wave, $k$ is the eastwest (zonal) wavenumber, $l$ is the north-south (meridional) wavenumber, $\beta$ is the north-south gradient of the planetary vorticity, and $R_{d}$ is the radius of deformation of the first baroclinic Rossby wave. Third, one of the goals here (similar to CS and ZW) is to compare observed Rossby wave speed with that obtained from the standard theory and provide details about such a comparison: for example, where is (geographically) the correspondence better, at what wavenumbers/frequencies, 


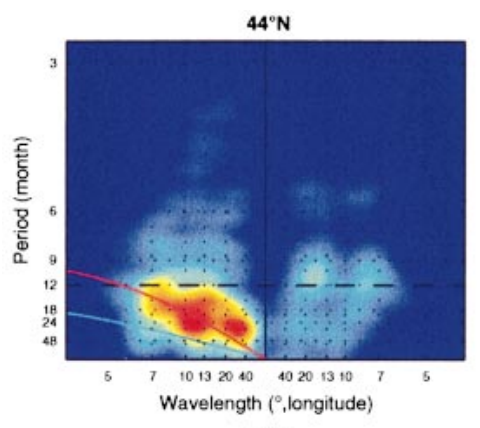

$43^{\circ} \mathrm{N}$

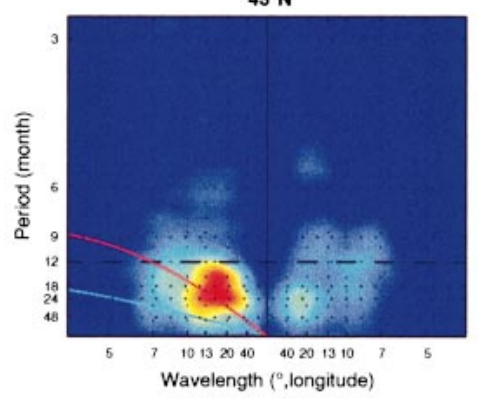

$42^{\circ} \mathrm{N}$

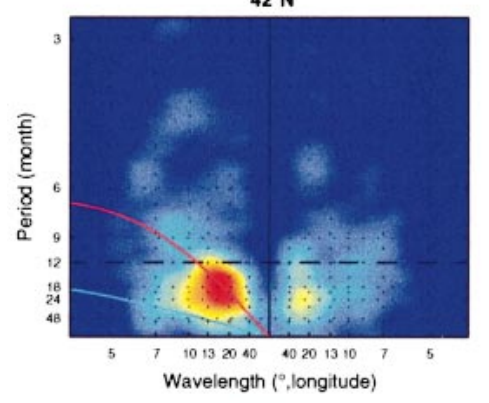

$41^{\circ} \mathrm{N}$

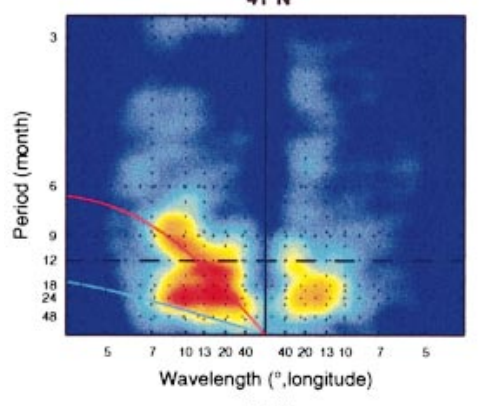

$40^{\circ} \mathrm{N}$

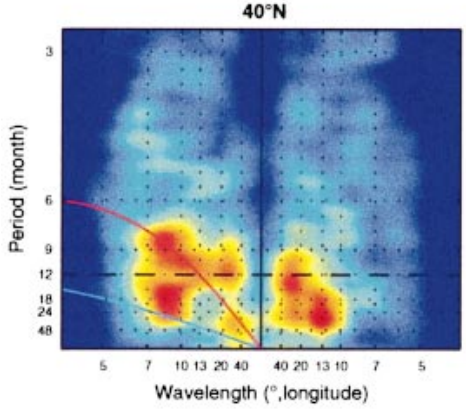

$39^{\circ} \mathrm{N}$

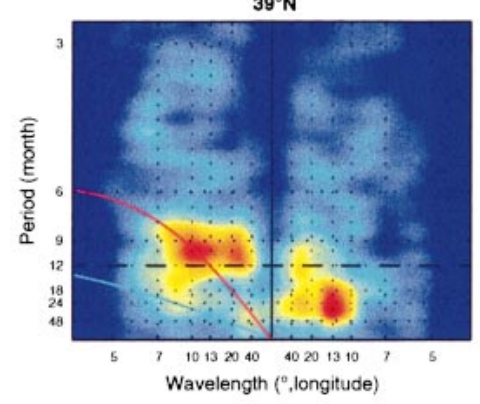

$38^{\circ} \mathrm{N}$

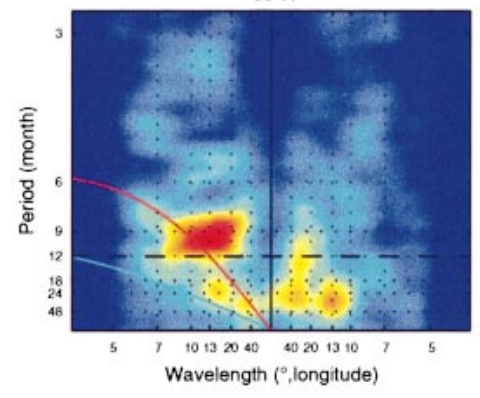

$37^{\circ} \mathrm{N}$

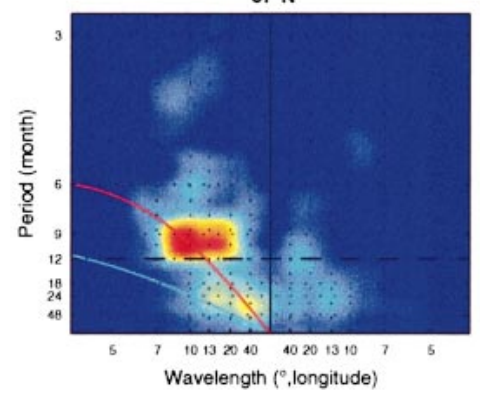

$36^{\circ} \mathrm{N}$

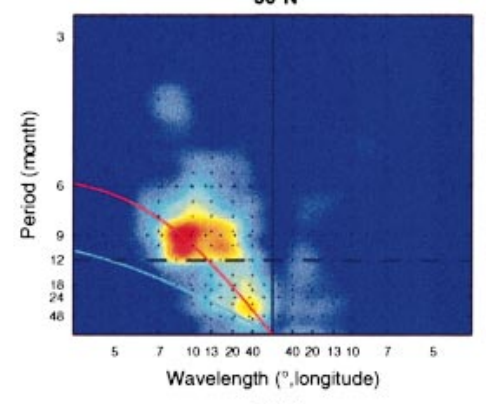

$35^{\circ} \mathrm{N}$
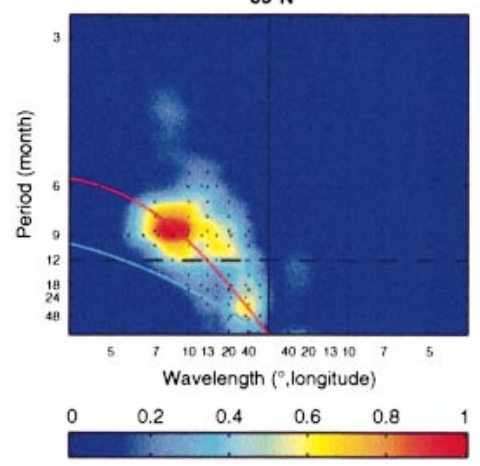

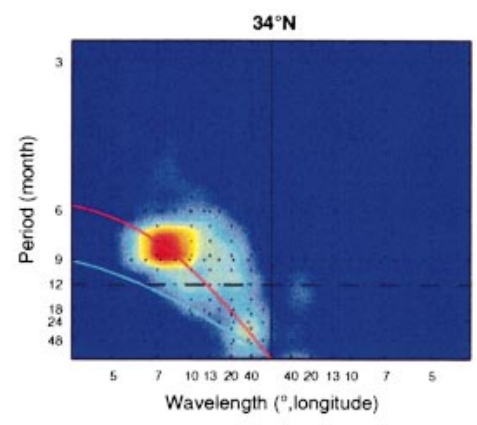

$33^{\circ} \mathrm{N}$

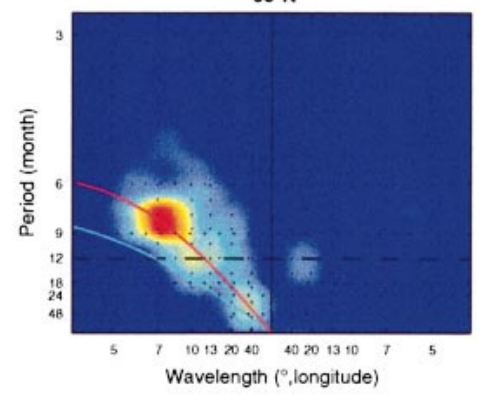

$32^{\circ} \mathrm{N}$

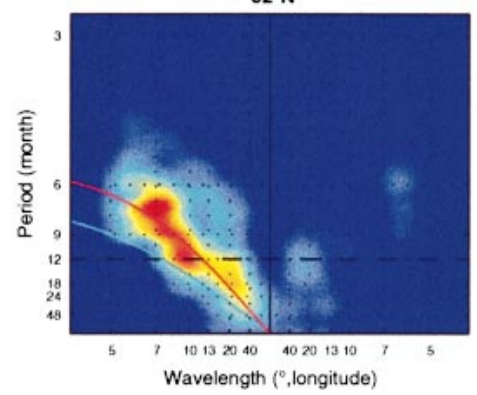

$31^{\circ} \mathrm{N}$

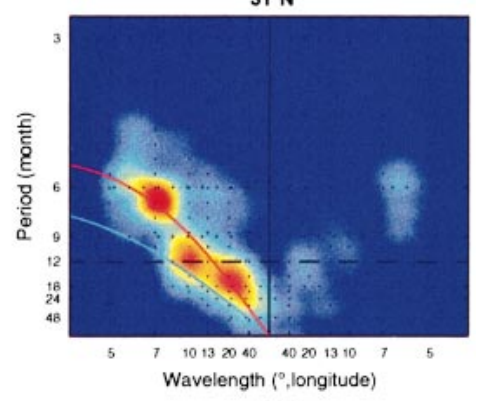

$30^{\circ} \mathrm{N}$

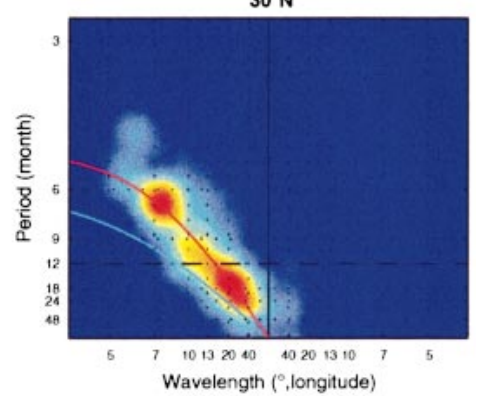

FIG. 2. Frequency-wavenumber spectra of anomalies at $30^{\circ}-44^{\circ} \mathrm{N}$. Magnitude is normalized by the maximum value at each latitude and is shown on a linear scale. The red line depicts the estimated dispersion diagram; the blue line corresponds to the theoretical dispersion diagram. 

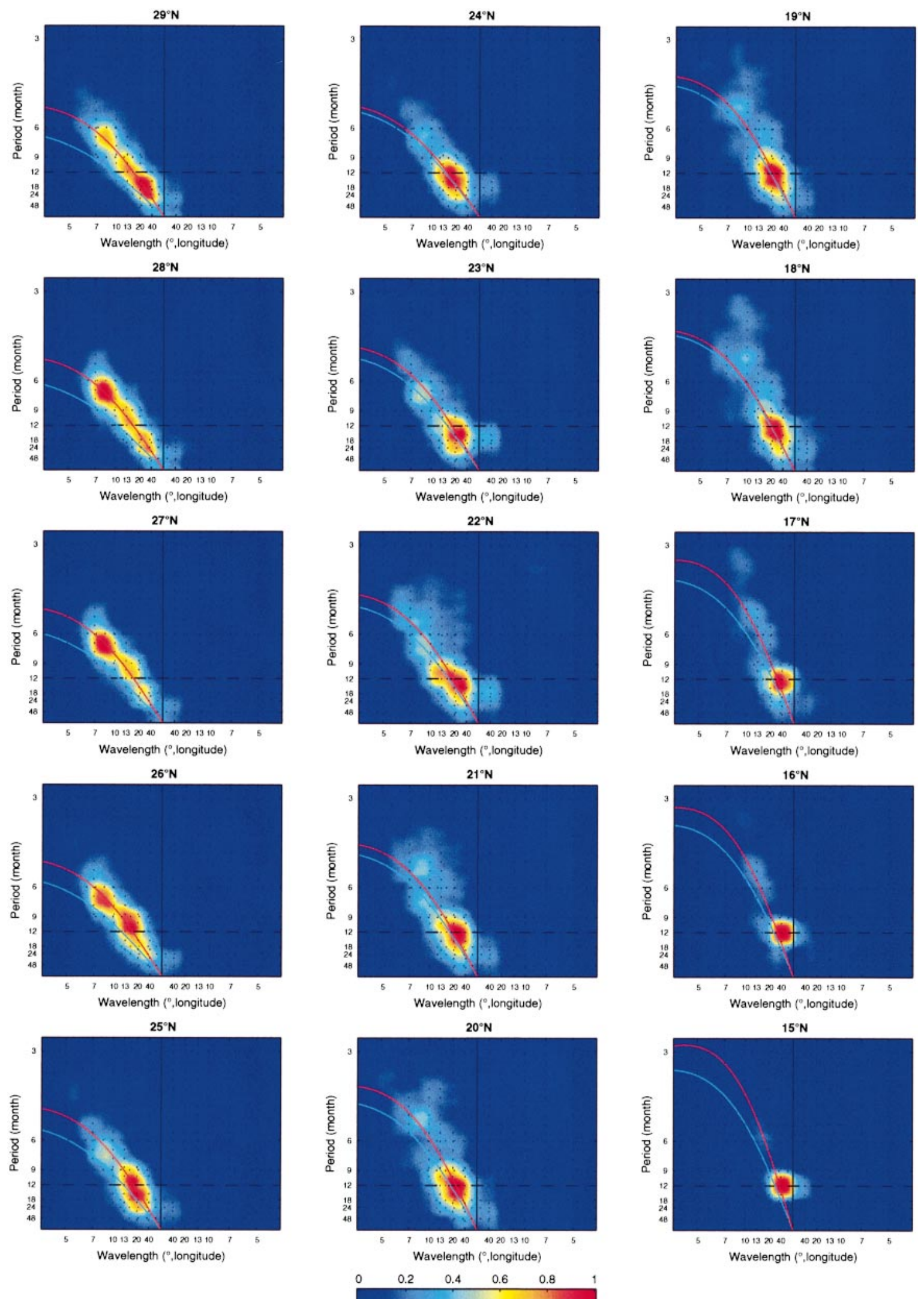

FIG. 3. Same as Fig. 2 but for $15^{\circ}-29^{\circ} \mathrm{N}$. 
and so on. Based on this, our approach was to fit the standard dispersion relation (1) to estimated SSH spectra, calculate associated phase speeds, and compare them with those expected from theory. (Details of the fitting procedure as well as estimation of errors associated with it can be found in the appendix.)

The best-fit (observed) dispersion curves are shown in red for each degree of latitude in Figs. 2 and 3 along with the underlying spectrum. Also plotted in these figures, in blue, are the "theoretical" dispersion curves. The latter were obtained from (1) with the Rossby radius of deformation estimated by Chelton et al. (1998) using a climatological average of vertical density profiles from in situ observations. (Here the quotation marks, which we drop hereinafter, are used to emphasize that empirical data were used in the calculation.) This is similar to the approach taken by CS and ZW.

The phase speed calculated from (1) depends on wavenumber/frequency. However, Figs. 2 and 3 show that most of the spectral peaks fall within the range of long nondispersive Rossby waves (for which the dispersion diagram is well approximated by a straight line). Therefore, to simplify a comparison, we used the longwave (nondispersive) approximation in calculation of the phase speed:

$$
C_{p}=-\beta R_{d}^{2}
$$

For the scales considered here (wavelength larger than $6^{\circ}$ longitude), the ratio of the difference between the phase speeds calculated for the dispersive (red curves in Figs. 2 and 3) and nondispersive (straight lines, not shown) case to the phase speed in the dispersive case did not exceed 5\% and did not affect any of the conclusions.

Inspection of Figs. 2 and 3 shows that at some latitudes between $25^{\circ}$ and $41^{\circ} \mathrm{N}$ the observed dispersion relation differs from that described by (1). At these latitudes spectral peaks were spread out over the broadest frequency-wavenumber range. In many cases the bestfit dispersion relation (red line) passes through a chain of the most energetic peaks. Yet, in some cases there was another zone of elevated energy that was close to but, nevertheless, separated from the best fit. For example, at $31^{\circ} \mathrm{N}$ the peak at the annual period falls below the estimated dispersion curve (Figs. 2 and 4). If one were to draw a line passing through the ridge of elevated energy in this spectrum (white line in Fig. 4), this line in the vicinity of the annual period would be located relatively closer to the theoretical dispersion curve (blue line). At shorter and longer periods it would turn and follow the estimated dispersion curve (red line). This is a manifestation of the fact emphasized by ZW that observed Rossby waves of different frequencies propagate with different speeds although their period and length scale remain within the theoretical nondispersive wave range. In light of the poor fit in some cases between (1) and the observed spectra, the procedure used to estimate $C_{p}$ was repeated for different frequency bands. In these

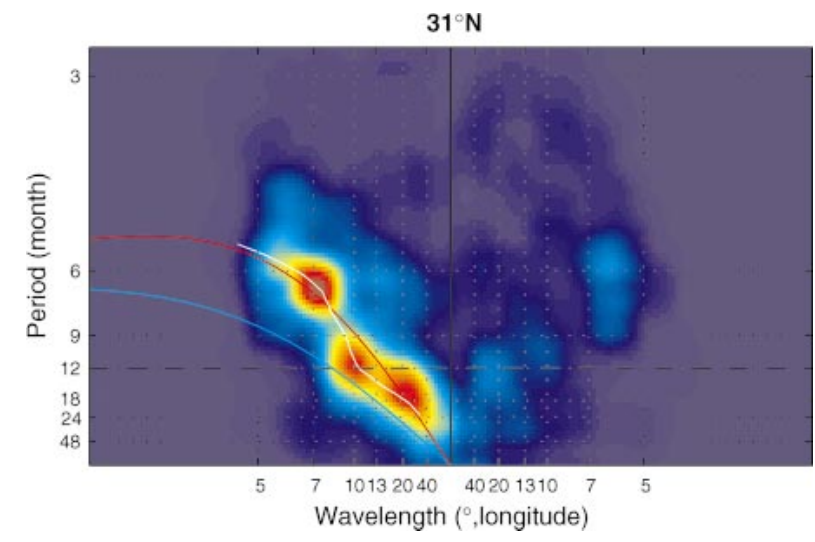

FIG. 4. The frequency-wavenumber spectrum of anomalies at $31^{\circ} \mathrm{N}$. The red line depicts the estimated dispersion diagram; the blue line corresponds to a theoretical dispersion diagram; the white line is the "eyeball"-drawn line passing through the ridge of high energy in the spectrum. See text for details.

cases, the spectral energy from a particular frequency band only, rather than from the entire spectrum, was used to estimate $C_{p}$. This may be thought of as a piecewise approximation to the unknown true dispersion relation by segments of curves (1). As a result our estimates may be, for instance, consistent with the theory leading to (1) for one frequency/wavenumber band while inconsistent for the other.

Last, it is important to recognize that the observed westward propagating anomalies are only compared to, rather than strictly identified with, the first mode baroclinic Rossby waves that satisfy the classical dispersion relationship (1). Similar to other papers on this subject [see Fu and Chelton (2001) for a comprehensive summary], this work only starts with the dynamics implied by (1). Although the general shape of the spectra is not inconsistent with Rossby wave dynamics, complete agreement between the observed signal and the standard theory leading to (1) is hardly expected because of a number of limitations of the latter. Accordingly, the term "Rossby waves" is applied to these anomalies in a broader sense than that implied by (1).

\section{Results}

Figures 2 and 3 show spectra for $15^{\circ}-44^{\circ} \mathrm{N}$. It is clearly seen that westward propagating anomalies dominate the signal at most latitudes. Energetic anomalies that move eastward are found between $38^{\circ}$ and $42^{\circ} \mathrm{N}$ and are, most probably, related to the Gulf Stream Extension.

Within the part of the spectra that characterizes westward propagation, most of the energy is found in the neighborhood of the estimated dispersion curve as expected from the fitting procedure. In addition, however, some peaks occur between the estimated and theoretical dispersion curves, but never at frequencies below the latter and rarely at frequencies higher than the former. 
Therefore, we identify this range as that corresponding to Rossby waves. In the following we first examine the meridional distribution of frequency and wavenumber, then the meridional distribution of phase speed, and finally the spatial structure of Rossby waves.

\section{a. Variation of frequency and wavenumber with latitude}

Figures 2 and 3 suggest that the North Atlantic can be separated into three regions based on the structure of the frequency-wavenumber spectra of the westward propagating anomalies.

1) To the north of $41^{\circ} \mathrm{N}$, the spectra show a single high energy region with periods larger than annual. The spectral energy reaches a maximum at periods between 1.5 and $2 \mathrm{yr}$ and wavelengths between $10^{\circ}$ and $15^{\circ}$ of longitude (order $800-1200 \mathrm{~km}$ ). There is negligible energy at annual or shorter periods.

2) In the region between $25^{\circ}$ and $41^{\circ} \mathrm{N}$, the spectra exhibit peaks with periods both longer and shorter than annual. In most cases the period of the dominant peak is less than the annual decreasing from north to south. To the north, between $40^{\circ}$ and $36^{\circ} \mathrm{N}$, the dominant peak ranges from 9 to 11 months while to the south, between $35^{\circ}$ and $25^{\circ} \mathrm{N}$, it ranges from 6 to 8 months. The relative amplitude of the dominant peak also decreases from north to south as does the wavelength, the latter ranging from $10^{\circ}-13^{\circ}$ of longitude $(800-1100 \mathrm{~km})$ in the northern part of the region to $7^{\circ}-10^{\circ}$ of longitude $(700-1000 \mathrm{~km})$ in the southern part. The dominant peak largely defines the estimated dispersion curve. A few less energetic peaks appear in the frequency-wavenumber region between the estimated and theoretical dispersion curves. The main secondary peak has a period longer than annual and tends to be closer than the dominant peak to the theoretical dispersion curve indicating that the longer observed waves propagate more slowly than the shorter ones. This finding is consistent with ZW.

3) To the south of $25^{\circ} \mathrm{N}$, annual waves tend to dominate. There is a trail of energy at shorter periods that gradually becomes negligible as one goes southward. In most cases this trail follows the estimated dispersion curve largely determined by the annual peak. The wavelength of the annual waves ranges from $15^{\circ}-$ $20^{\circ}$ of longitude at $25^{\circ} \mathrm{N}(1500-2000 \mathrm{~km})$ to about $40^{\circ}$ of longitude south of $15^{\circ} \mathrm{N}(>4000 \mathrm{~km})$.

These three regions are well delineated in Figs. 5a and $5 \mathrm{~b}$, which show meridional changes in the integrated spectral energy of westward-propagating anomalies versus frequency, and, separately, versus wavenumber. Figure 5a shows that the spectral energy is limited to periods longer than annual to the north of $41^{\circ} \mathrm{N}$ (region 1). Between $25^{\circ}$ and $41^{\circ} \mathrm{N}$ (region 2), the spectrum is richer; that is, it is spread out in frequency, with peaks often occurring at periods shorter and longer than annual at the same latitude. To the south of $25^{\circ} \mathrm{N}$ (region 3 ) the spectrum narrows, being dominated by an annual peak. Figure $5 \mathrm{~b}$ shows the corresponding changes in the wavelength of the observed Rossby waves.

The North Atlantic is sufficiently wide in the $25^{\circ}-$ $40^{\circ} \mathrm{N}$ range for an analysis of zonal differences in Rossby wave properties. To this end, we estimated spectra based on nonoverlapping sections of data covering regions to the west and to the east of the Mid-Atlantic Ridge. Figures $6 \mathrm{a}$ and $6 \mathrm{c}$ show the meridional dependence of integrated spectral energy versus frequency for the western and for the eastern parts of the North Atlantic. These spectra demonstrate that the western side of the basin is more energetic at all frequencies than the eastern side. The difference is especially large north of $33^{\circ} \mathrm{N}$. A zone of increased energy in the western part occurs in the $7-11$ month range between $34^{\circ}$ and $40^{\circ} \mathrm{N}$. In the eastern part of the basin, a maximum in the Rossby wave energy occurs between $32^{\circ}$ and $34^{\circ} \mathrm{N}$, that is, slightly to the south of the maximum in the western part, and at longer periods, 12-18 months. The ratio of the spectral energy at a particular frequency over the total energy at a given latitude in the side of the basin being considered (Figs. 6b,d) shows that waves of shorter than annual period dominate the western part of the North Atlantic over the meridional range considered here, $25^{\circ}-40^{\circ} \mathrm{N}$. In the eastern part, this is true only between $36^{\circ}$ and $37^{\circ} \mathrm{N}$ and south of $29^{\circ} \mathrm{N}$.

\section{b. Variation of phase speed with latitude}

The meridional distribution of $C_{p}$ evaluated from the spectra as well as the associated estimated errors are shown in Fig. 7a. The uncertainties of the estimates (error bars in the figure) depend on the resolution of the estimated spectrum and on the shape of the spectrum itself, that is, on the underlying ocean dynamics. At a given latitude, smaller errors result from a narrower spectral resolution and from the dominance of Rossby waves in dynamics. (See the appendix for a discussion of the calculation of errors.) However, this is true only if the spectral peaks associated with the waves are adequately resolved; that is, both spatial and temporal scales of the waves are small compared with the corresponding length of the data record. Estimates of uncertainty (Fig. 7) show that the data and their processing allow confident identification of Rossby waves between $15^{\circ}$ and $47^{\circ} \mathrm{N}$. North of $47^{\circ} \mathrm{N}$ the period of the waves becomes too long to be resolved with the data we have, while south of $15^{\circ} \mathrm{N}$ the large zonal length scale of the waves becomes a limiting factor. Although the errors between $40^{\circ}$ and $43^{\circ} \mathrm{N}$ are relatively large, these errors resulted from a broad spectrum (Fig. 2) associated with the complicated dynamics in this area rather than from poor spectral resolution. The smooth change of $C_{p}$ in the meridional direction lends additional credibility to the estimates in this range of latitude. Further analysis 
(a)

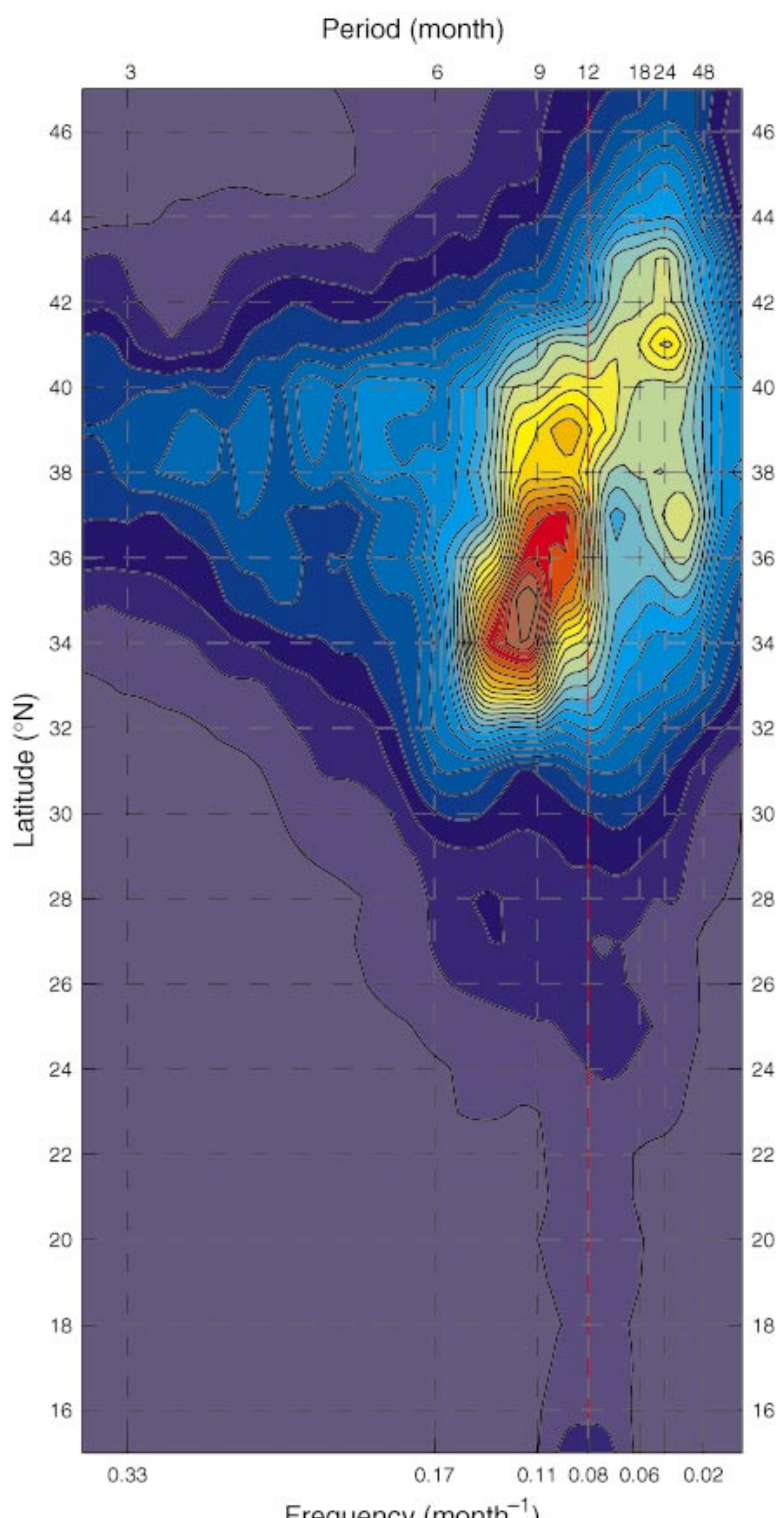

(b)

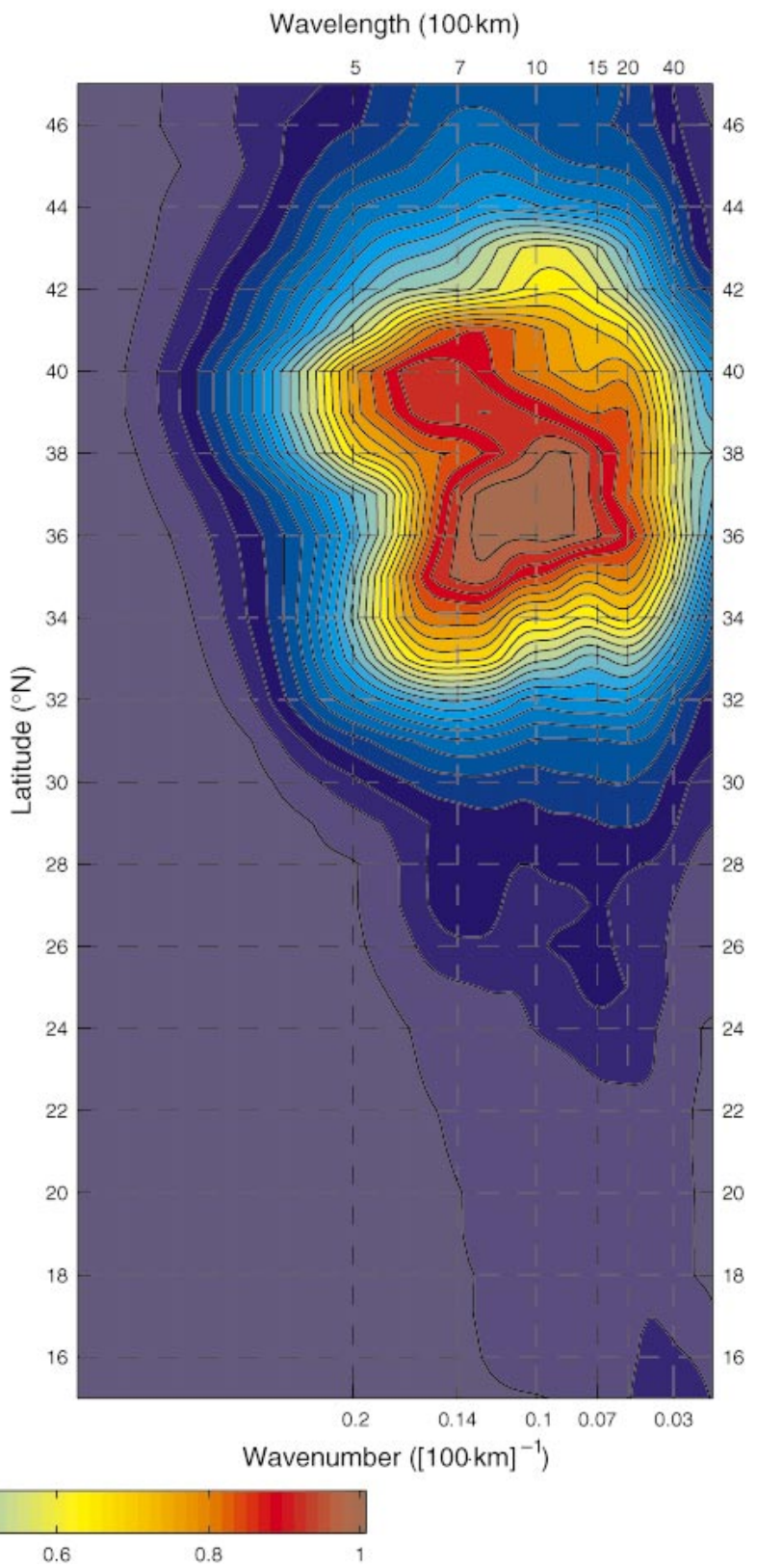

FIG. 5. Integrated spectral energy of westward propagating anomalies: (a) distribution of energy vs frequency as a function of latitude and (b) distribution of energy vs wavenumber as a function of latitude.

relates only to the region between $15^{\circ}$ and $47^{\circ} \mathrm{N}$ or to subregions within this range.

Figure 7 demonstrates that the observed speed of what we believe to be Rossby waves exceeds that expected from classical theory at all latitudes considered, between $15^{\circ}$ and $47^{\circ} \mathrm{N}$. Furthermore, this difference increases to the north from $10 \%-20 \%$ between $15^{\circ}$ and $25^{\circ} \mathrm{N}$ to a maximum of about $300 \%$ at $42^{\circ} \mathrm{N}$ (Fig. $7 \mathrm{~b}$ ). This is also seen in the difference between the slopes of the estimated dispersion curves (red lines in Figs. 2 and 3) and the theoretical curves (blue lines). Between $44^{\circ}$ and $47^{\circ} \mathrm{N}$, observed waves are about twice as fast as the theoretical ones. Qualitatively, this is consistent with the estimate of CS.

The discrepancies between observations and theory may result from inadequacies in the theory as well as from errors (shown in Fig. 7) in the estimates. In addition, recall that the theoretical values of $C_{p}$ shown in Fig. 7 are estimates (Chelton et al. 1998) based on climatological in situ data. The errors associated with these 
(a)

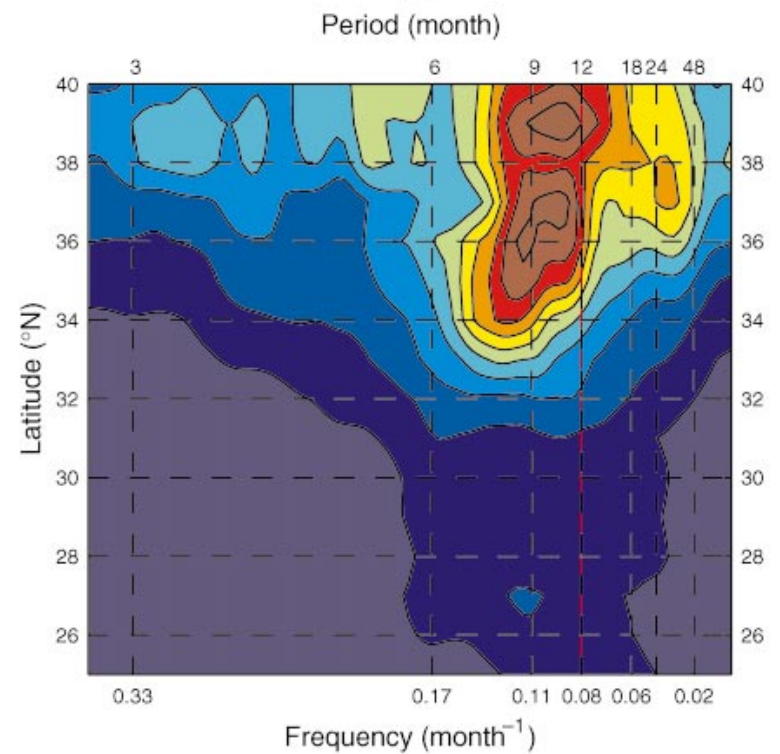

(c)

Period (month)

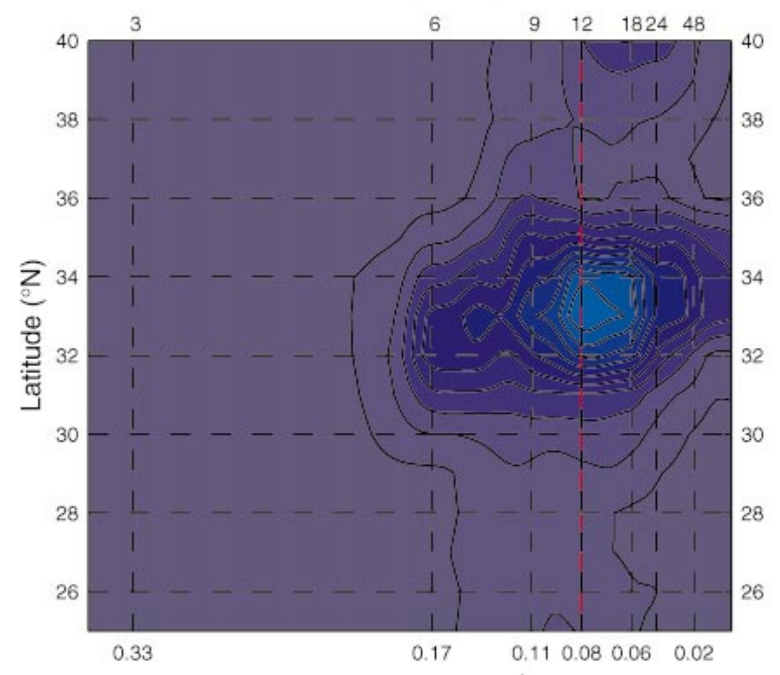

Frequency $\left(\right.$ month $\left.^{-1}\right)$ (b)

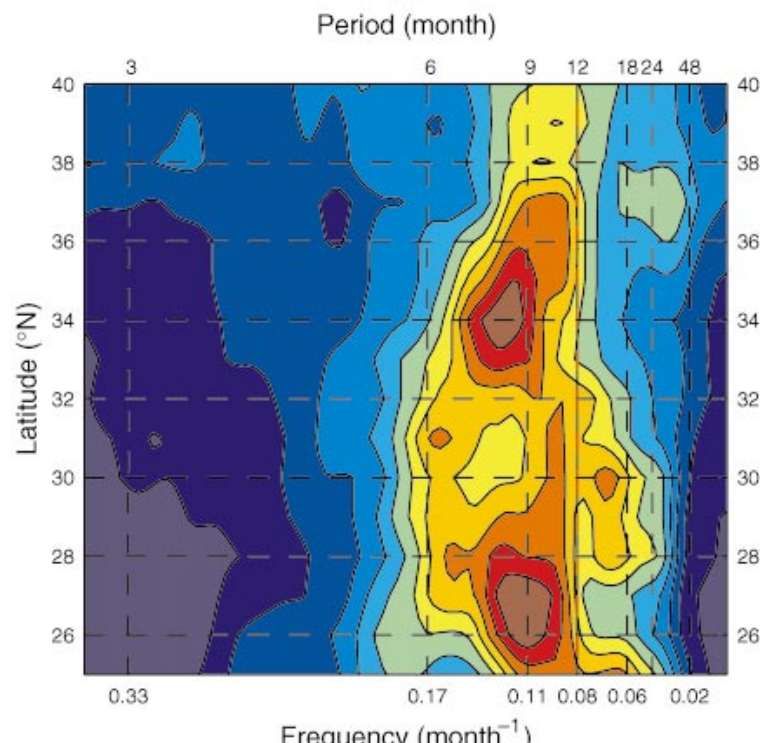

(d)

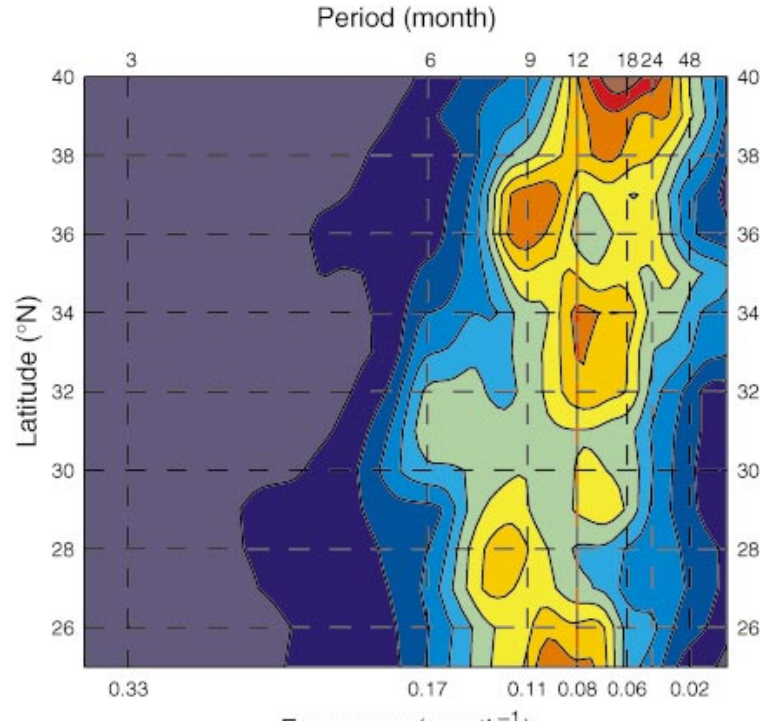

Frequency $\left(\right.$ month $^{-1}$ )

FIG. 6. Distribution of spectral energy in the western and in the eastern part of the North Atlantic: (a) distribution of energy vs frequency as a function of latitude in the western part, (b) fraction of energy at a particular frequency to the total energy at a given latitude in the western part, and (c) and (d) similar to (a) and (b) but for the eastern part. The same color scale is used for all plots. Energy in (a) and (c) is normalized by its maximum in the western part; fraction of energy in (b) and (d) is normalized by its maximum value in the western and eastern parts, respectively.

estimates are difficult to evaluate. Chelton et al. (1998) argue that these errors do not exceed a few percent, except near intense currents. Subsequently, they conclude that the bias in the observed values (based on $\mathrm{SSH}$ ) is too high to be accounted for by the uncertainties. Our results support their conclusion.

The meridional distribution of observed $C_{p}$ reveals a region of almost uniform magnitude between $32^{\circ}$ and $40^{\circ} \mathrm{N}$. Within this region the observed phase speed is a little less than $4 \mathrm{~cm} \mathrm{~s}^{-1}$, while the theoretical $C_{p}$ decreases monotonically from 3 to $1 \mathrm{~cm} \mathrm{~s}^{-1}$. Between $42^{\circ}$ and $45^{\circ} \mathrm{N}$, the best-fit $C_{p}$ decreases from 4 to $2 \mathrm{~cm} \mathrm{~s}^{-1}$. Between $15^{\circ}$ and $25^{\circ} \mathrm{N}$, the observed phase speed is statistically consistent with theory although systematically biased towards higher values.

Given the increase in phase speed from east to west 
(a)

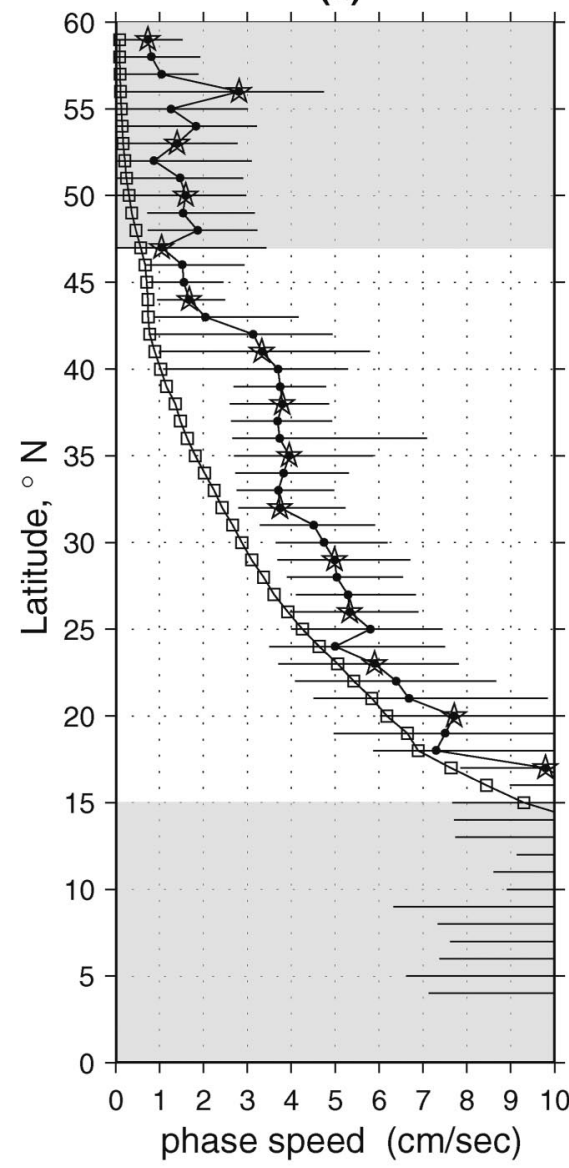

(b)

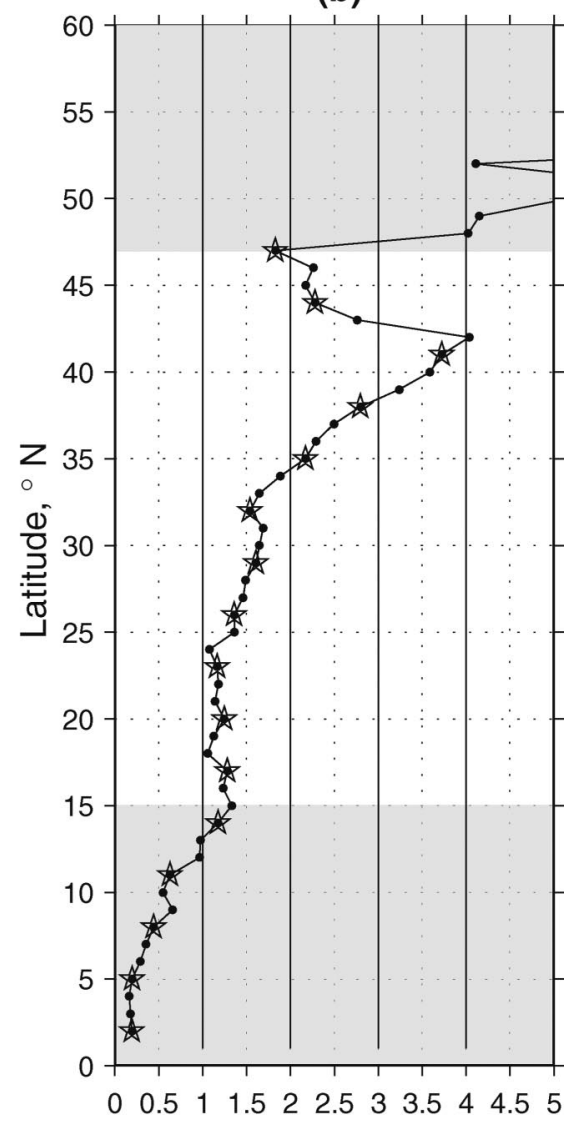

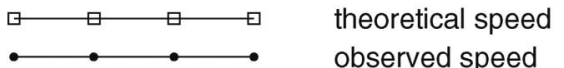

FIG. 7. Comparison of (a) Rossby wave phase speed and (b) ratio of the best-fit Rossby wave phase speed with that expected from theory. See text for more details. Stars denote independent estimates from SSH spectra. Uncertainties estimated from 95\% confidence level for a peak in an integrated spectrum (see the appendix). Accurate results are obtained for $15^{\circ}-47^{\circ} \mathrm{N}$. Regions of unreliable estimates are shaded.

found by CS as well as the ZW observation that the phase speed varies with wavenumber, we also analyze the phase speed by subbasin and by frequency/wavenumber (Fig. 8). In strict terms, the uncertainty does not allow a more precise statement than that of consistency of the estimates with one another. (In Fig. 8, error bars for different estimates, i.e., for those made for different subbasins and/or for different wavenumber/frequency bands, overlap.) The difference between the estimates exposes itself only via a bias, albeit a persistent one judging from the change of the estimates with latitude. Thus, based on a bias, shorter waves (7-11-month period) were found to propagate faster than longer ones (annual and longer period) in both the eastern and western parts of the North Atlantic. Also, both shorter and longer waves were found to propagate up to $20 \%$ faster in the western side of the basin than in the eastern side. Chelton and Schlax found a higher, up to $50 \%$, differ- ence in the speed of Rossby waves between the western and the eastern basins in the Pacific, although they considered the most remote east-west parts of the ocean rather than an average over the two halves. Interestingly, the difference between the speeds of waves of different wavenumber/frequency bands in the same subbasin is larger than that of the waves of the same wavenumber/ frequency band in different subbasins.

On both sides of the North Atlantic, the change in the observed phase speed of longer waves (Fig. 8b) as a function of latitude is quite similar to that predicted by theory. By contrast the speed of the observed shorter waves (Fig. 8a) does not decrease to the north as quickly as the theoretical speed does: on the eastern side of the basin between $25^{\circ}$ and $40^{\circ} \mathrm{N}$ the observed speed of these waves decreases from 5 to $3 \mathrm{~cm} \mathrm{~s}^{-1}$ while the theoretical one decreases from 4 to $1 \mathrm{~cm} \mathrm{~s}^{-1}$; on the western side, the difference in the rate of change is especially large 
(a)

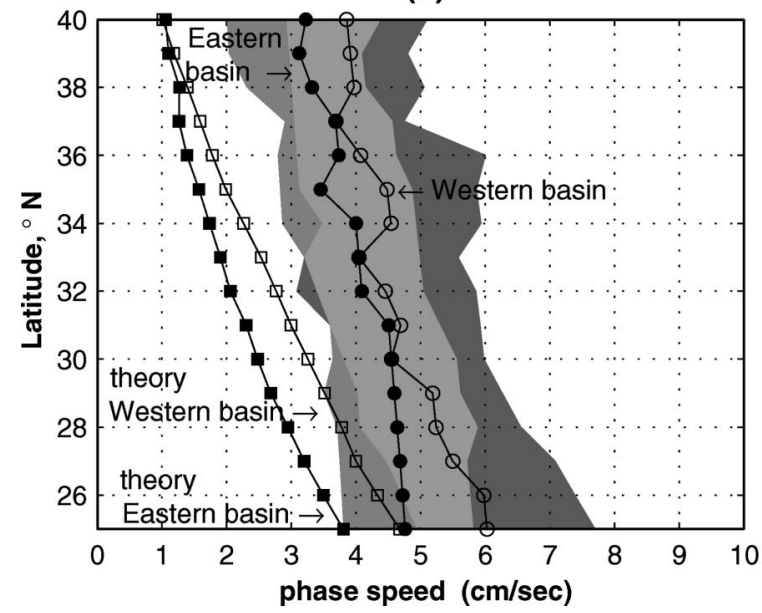

(b)

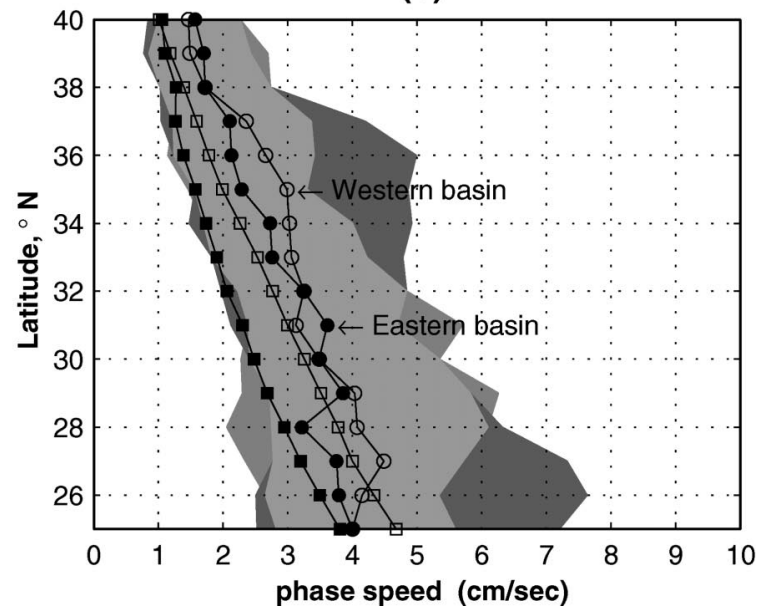

FIG. 8. Comparison of phase speed of shorter (7-11-month period) and longer (annual and longer period) Rossby waves in the western and in the eastern part of the North Atlantic: (a) shorter waves in two basins and (b) longer waves in two basins. Theoretical curves are the same in (a) and (b) and are labeled only in (a). Uncertainties are shown in shades of gray: the darkest shade relates to the western basin; the lightest, to the eastern basin; the intermediate, to the region where the two overlap.

between $30^{\circ}$ and $40^{\circ} \mathrm{N}$ where the observed speed is almost uniform (it varies between 4.5 and a little less than $4 \mathrm{~cm} \mathrm{~s}^{-1}$ ) while the theoretical speed decreases monotonically from a little over 3 to $1 \mathrm{~cm} \mathrm{~s}^{-1}$.

\section{c. Spatial structure of Rossby waves}

To better understand the spatial structure of the Rossby wave field, the Rossby wave signal was extracted by application of a two-dimensional bandpass finite impulse response filter. This filter, designed in the Fourier domain, passed all frequency-wavenumbers located in the Rossby wave range (primarily between the observed and theoretical dispersion curves; Fig. 9). Outside this region the magnitude of the filter frequency response decreased from 1 to 0 as the cosine squared to suppress the Gibbs effect upon inversion from the Fourier to the time-longitude domain. This step resulted in time-longitude arrays at each latitude, filtered to include only contributions from the Rossby wave portion of the spectrum. It is important to note that the time-longitude section at each latitude was filtered independently from the others so that no additional north-south coherency was imposed on the data in this process.

For each spatial grid point the root-mean-square of the filtered sea surface elevation in time was calculated from the filtered arrays, yielding an estimate of the total amplitude of the Rossby wave field. Similarly, the rootmean-square was calculated for each spatial grid point for the shorter and longer waves after the arrays were
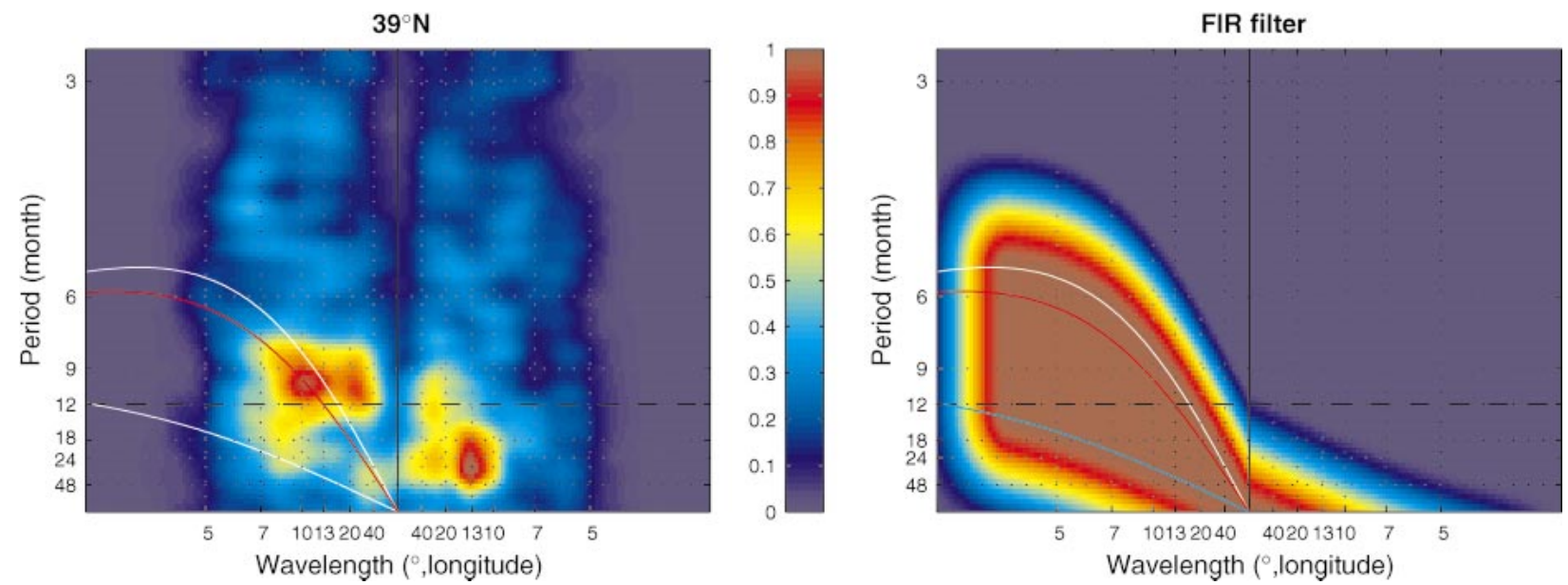

FIG. 9. An example of the frequency-wavenumber spectrum of anomalies at $39^{\circ} \mathrm{N}$ and the magnitude of the frequency response of the filter used to extract the Rossby wave signal at this latitude. The red line depicts the best-fit dispersion curve; the blue line corresponds to the theoretical dispersion curve and defines the low-frequency limit of the filter pass band; the white line shows the high-frequency limit of the filter pass band and corresponds to a dispersion curve associated with the upper confidence limit of the best-fit dispersion curve. 


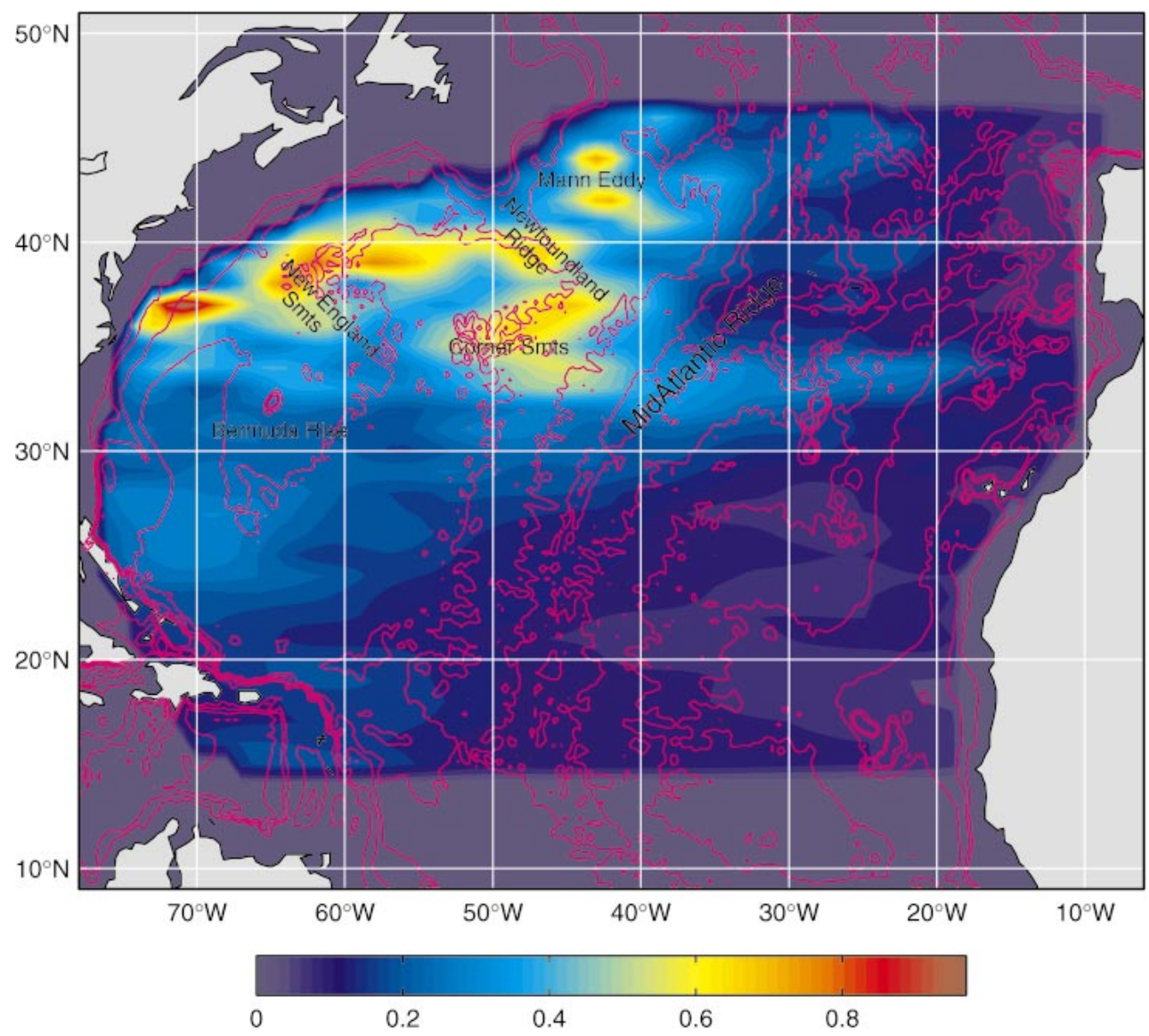

FIG. 10. Estimated amplitude of Rossby waves (normalized by its maximum value). Contours show bottom depth of 2000, 3000, 4000, and $5000 \mathrm{~m}$.

additionally filtered in time to include only the relevant periods. The results for the total Rossby wave field, for its shorter and for its longer constituents, are qualitatively similar, and so only those associated with the total Rossby wave signal are presented here (see Fig. 10).

The largest amplitudes are found in the vicinity of the Gulf Stream and the North Atlantic Current (north of the Newfoundland Ridge), in particular where the stream crosses the continental slope, the New England Seamounts, and the Newfoundland Ridge as well as in the region of the Mann Eddy (Mann 1967). The area of the Gulf Stream and its extension was identified as a generation region for the first baroclinic Rossby waves in the modeling study of Hermann and Krauss (1989). They found that in this region the waves resulted from nonlinear energy transfers. However, if indeed the westward-propagating anomalies are governed primarily by Rossby-wave-like dynamics, then, based on classical linear theory, their energy flux should be directed predominantly westward. This means that little to no energy from this region penetrates the ocean interior except, possibly, for the section of the Gulf Stream between the New England Seamounts and the Newfoundland Ridge (more on this below).
At this point, we emphasize that, consistent with the spectral plots of Fig. 6, Fig. 10 shows higher amplitudes of the Rossby waves west of the Mid-Atlantic Ridge than east of it. However, direct influence of the MidAtlantic Ridge seems to be limited to $30^{\circ}-45^{\circ} \mathrm{N}$, where the ridge is taller and wider than in other areas. [A similar region of increased amplitude was reported by Schlax and Chelton (1994) and Polito and Cornillon (1997) based on TOPEX/Poseidon data and by Tokmakian and Challenor (1993) based on Geosat data.] However, this is also the area where one expects significant activity associated with the Gulf Stream and the North Atlantic Current. For example, the regions of the highest wave amplitude closest to the Mid-Atlantic Ridge are found in the vicinity of the Mann Eddy, an integral part of the North Atlantic Current system, and near the Corner Seamounts, possibly a result of their (rather than Mid-Atlantic Ridge) influence on a branch of the Gulf Stream circulation. Thus, with the data available here one cannot justify the increase in the wave amplitude only by the direct influence of the Mid-Atlantic Ridge.

Analysis of the complex empirical orthogonal functions (CEOFs; Preisendorfer 1988) of the Rossby wave 
signal provides further details about the distribution of the wave amplitude and propagation of the waves. Figure 11 shows a sequence of the sum of the first two CEOFs in the 7-11-month period range (waves of these scales are most energetic between $25^{\circ}$ and $40^{\circ} \mathrm{N}$ ) extracted from the data. These CEOFs account for $65 \%$ of the total Rossby wave variance in this frequency band.

Clearly evident in Fig. 11 is the large coherence of the Rossby waves over a range of latitudes. In the western half of the basin wave crests/troughs are well defined over at least $10^{\circ}$ of latitude south of $35^{\circ} \mathrm{N}$, while in the eastern half of the basin crests/troughs are well defined over at least $15^{\circ}$ of latitude. This differs from the CS observation that in the midlatitudes anomalies do not exhibit coherent structure in the north-south direction outside their generation region. Apparently, in our case a more persistent coherency was revealed due to separation of the wave field into different components.

The Mid-Atlantic Ridge appears as a clear boundary in the orientation of Rossby waves. East of the MidAtlantic Ridge the waves are oriented generally from southwest to northeast. This orientation is consistent with generation of the waves along the eastern boundary with subsequent $\beta$ refraction during westward propagation. [For a discussion on generation of Rossby waves off the eastern boundary see, e.g., Hermann and Krauss (1989) and Gerdes and Wübber (1991).] West of the Mid-Atlantic Ridge, wave fronts are oriented in the southeast-northwest direction, which is unexpected if the waves were to continue from the eastern half of the basin or if they were to originate along a substantial north-south section of the Mid-Atlantic Ridge.

Figure 11 shows that individual fronts do not smoothly pass from the eastern side of the North Atlantic to the western side. In fact, after generation along a considerable portion of the eastern boundary, the waves preserve a coherent structure while propagating westward, but then lose it upon transmission over the ridge, especially over its wider and taller part north of $30^{\circ} \mathrm{N}$ where the topographic scale in the east-west direction is larger than the wavelength. Wave fronts west of the Mid-Atlantic Ridge appear to originate from a relatively small area southeast of the Grand Banks in the Gulf Stream Extension region (approximately $35^{\circ}-40^{\circ} \mathrm{N}$, $\left.40^{\circ}-50^{\circ} \mathrm{W}\right)$. In this region the waves have the largest amplitude overall and are oriented parallel to the axis of the Newfoundland Ridge. Such a spatial configuration of the westward propagating anomaly field at periods in the semiannual-annual range was insensitive to a variation in the details of the fashion in which the waves were extracted such as the exact frequency band, type of filters applied before CEOF decomposition, and inclusion of one or two leading CEOFs; that is, wave orientation is a robust feature of our processing. Physically, a maximum in the wave energy may result from wave interference or from a change of the waveguide characteristics. However, the location and orientation of the maximum, in the vicinity of and parallel to the New- foundland Ridge, as well as the existence of strong currents in this region leads us to suggest that this area is a source of the waves in the western part of the North Atlantic. Presumably, this source originates from the interaction of the Gulf Stream and/or the deep western boundary current (DWBC) with the bottom topography. Apparently, this interaction leads to a deviation of the Gulf Stream path from the mean west-east direction and to separation of the DWBC, or at least of some portion of it, from the continental slope. This causes significant anomalies in the water structure in the vicinity of the Grand Banks. We anticipate that at least part of the energy of these anomalies spread in the form of Rossby waves as a result of an adjustment process. Therefore this spreading should have a large westward component. Details of the propagation, however, can be affected by the complex dynamical background in the region. Figure 11 shows that these disturbances spread to the southwest and their crests gradually extend to the southeast. These disturbances can be traced all the way to the Antilles and Bahama Islands (see progression of the dark blue lines in Fig. 11).

Note that our suggestion that the most energetic waves in the wavenumber-frequency portion of the spectrum corresponding to Rossby waves in the North Atlantic appear to result from interaction of the Gulf Stream/DWBC with the Newfoundland Ridge is different from the theory of Rossby wave radiation from the Gulf Stream due to meandering of its path, presumably, between Cape Hatteras and the Grand Banks [Kamenkovich and Pedlosky (1998) review this subject and provide its most recent development]. Essentially, the radiation theory assumes that the time-dependent far field is represented by Rossby waves corresponding to the classical Rossby wave theory and that disturbances that radiate from the meandering Gulf Stream have to match the classical Rossby wave field. This implies that south of the stream, energy of the radiating waves propagates south (from the Gulf Stream) and west (to accommodate the far field). Then, the classical theory demands northeast-southwest phase (front) orientation for radiating waves. Indeed, our results show that sometimes in a region to the east of the New England Seamounts (between $50^{\circ}$ and $60^{\circ} \mathrm{W}$ ) observed wave fronts exhibit such an orientation (e.g., see images for 1995 in Fig. 11). However, this pattern is not persistent in time and does not spread southward beyond $35^{\circ} \mathrm{N}$. By contrast, the northwest-southeast oriented anomalies dominate most of the time and over a larger region of the western North Atlantic. Interestingly, following the classical theory, the observed (northwest-southeast) orientation implies that the flux of Rossby wave energy would be to the northwest. Hence, if these anomalies correspond to classical Rossby waves, their amplitude should increase to the northwest as the waves propagate to the southwest. However, this is not what is observed; the observed waves appear to propagate to the southwest with little decrease in wave amplitude to the southeast. If anything, 

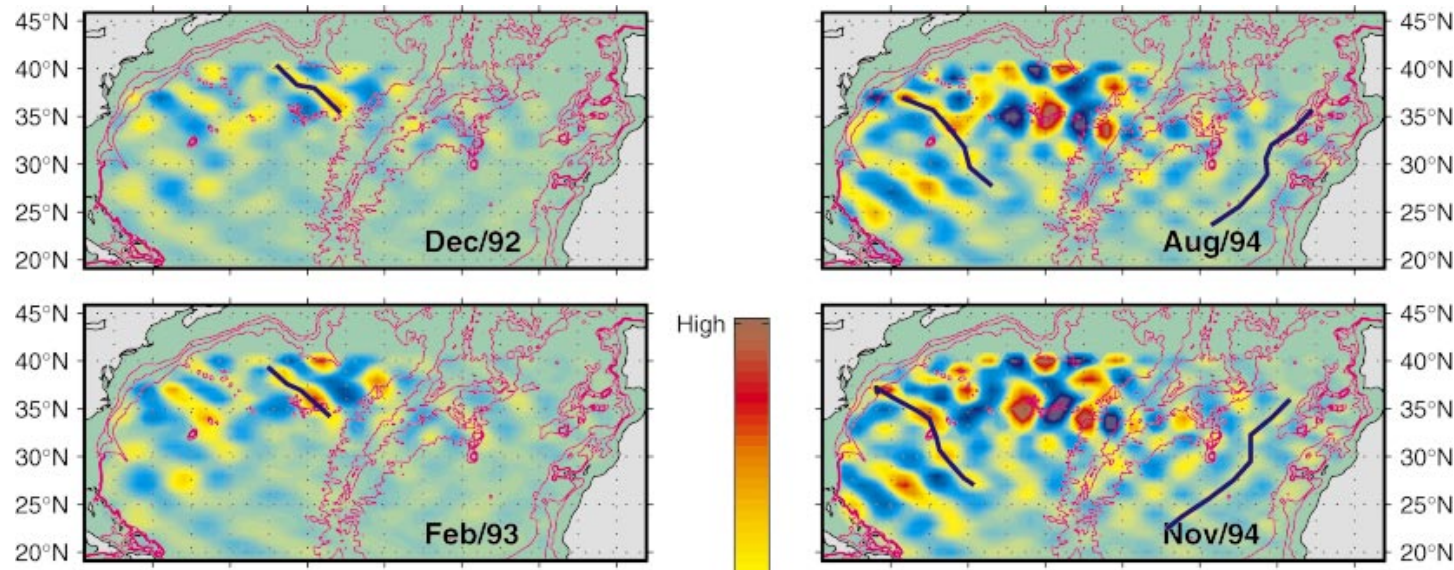

$45^{\circ} \mathrm{N}$
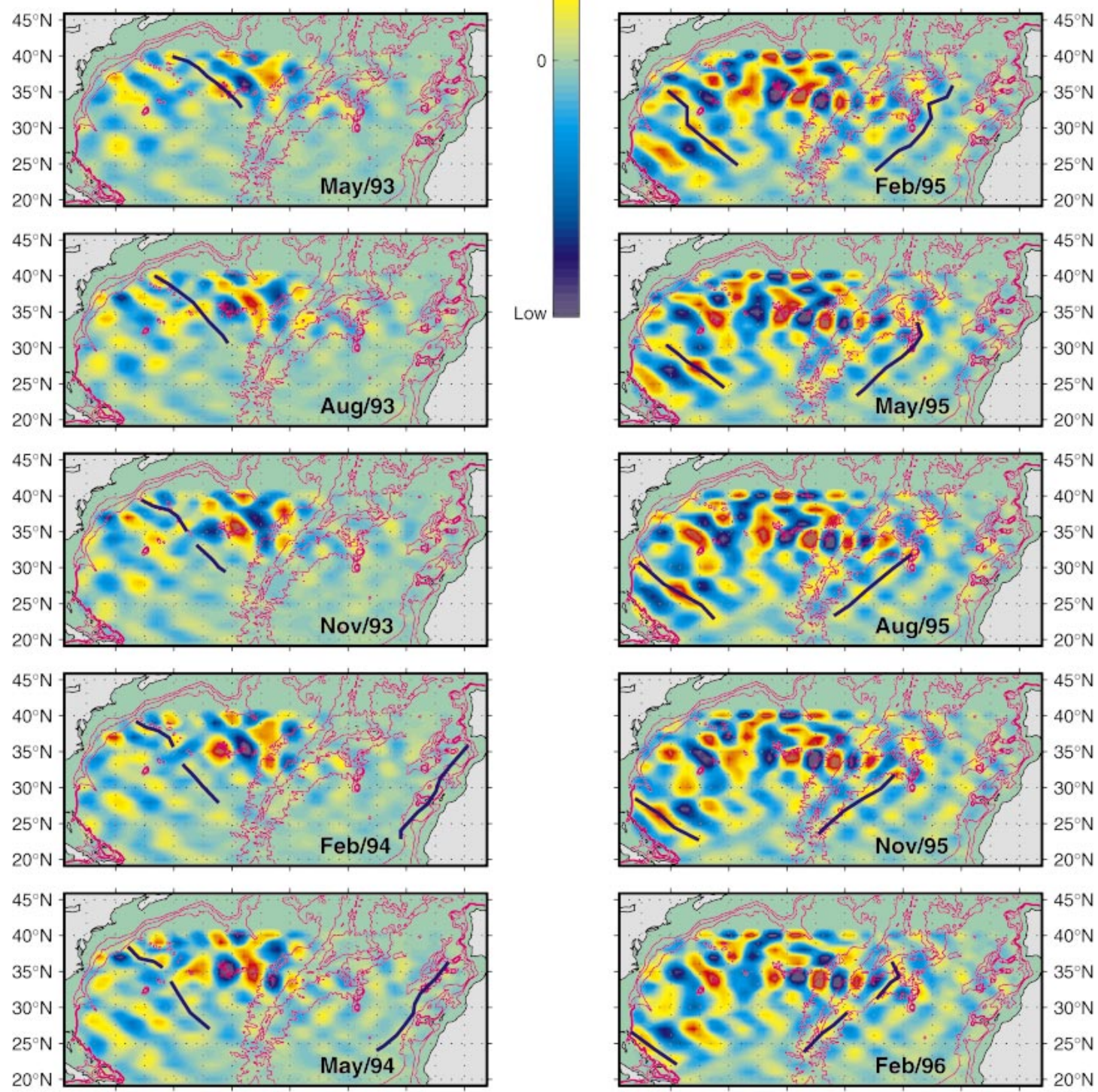

$70^{\circ} \mathrm{W} 60^{\circ} \mathrm{W} 50^{\circ} \mathrm{W} \quad 40^{\circ} \mathrm{W} 30^{\circ} \mathrm{W} 20^{\circ} \mathrm{W} \quad 10^{\circ} \mathrm{W}$

$70^{\circ} \mathrm{W} 60^{\circ} \mathrm{W} 50^{\circ} \mathrm{W} \quad 40^{\circ} \mathrm{W} 30^{\circ} \mathrm{W} 20^{\circ} \mathrm{W} 10^{\circ} \mathrm{W}$

FIG. 11. Sum of the two first complex empirical orthogonal functions of the Rossby wave field in the 7-11-month period range. Color scale is the same for all plots. Blue lines demonstrate propagation of individual wave fronts in the western and in the eastern parts of the basin. 
wave energy appears to spread in the direction of the phase propagation, to the southwest. This suggests, once again, that these anomalies do not correspond to classical Rossby waves or that processes not accounted for in the simple linear theory such as sheared, time dependent currents, wind forcing, complex topography, and so on, play a significant role in the characteristics of Rossby waves in this part of the North Atlantic.

\section{Conclusions}

Analysis of the SSH anomaly field in the Rossby wave portion of the frequency-wavenumber spectrum in the North Atlantic between $15^{\circ}$ and $47^{\circ} \mathrm{N}$ suggests that this region can be divided into three subregions based on the spectral composition of the observed waves. South of $25^{\circ} \mathrm{N}$ annual period waves dominate. North of $40^{\circ} \mathrm{N}$ only waves with periods larger than annual exist. Between $25^{\circ}$ and $40^{\circ} \mathrm{N}$, the spectral content of the anomaly field is more complex. Here, constituents of annual and longer periods play a secondary role to those of shorter than annual period, especially in the western part of the basin. The most energetic waves in the North Atlantic were found in the western subbasin between $34^{\circ}$ and $40^{\circ} \mathrm{N}$ with periods in the 7-11-month range.

Qualitatively, our result that westward propagation of anomalies observed in altimeter-derived sea surface height fields is faster than expected from classical Rossby wave theory (1) agrees with that of CS. Also, our result that the difference between best-fit phase speeds and those obtained theoretically depends strongly on wavelength/period, with shorter waves (subannual periods in our case) propagating substantially faster and longer waves propagating at very nearly the theoretical speeds is consistent with that of $\mathrm{ZW}$.

Not surprising, as the proportion of shorter waves in the total Rossby wave field at a given latitude increases the difference between the theoretical and best-fit speeds of propagation averaged over all wavelengths increases, too. The observed waves propagate at speeds similar to those expected from theory between $15^{\circ}$ and $25^{\circ} \mathrm{N}$ where the annual waves dominate, while farther to the north, shorter than annual waves come into play and, accordingly, the discrepancy in the phase speeds grows until it reaches a maximum at about $40^{\circ} \mathrm{N}$, north of which the energy of the short waves becomes negligible again.

The physical mechanisms responsible for the difference in the best-fit and theoretical speeds remain to be determined. [See review of related theories in $\mathrm{Fu}$ and Chelton (2001).] Certainly, an environment that does not comply with the assumptions of the classical theory (forcing, background currents, nonuniform bottom topography, etc.) distorts propagation of the waves. Our results show that the northward decrease in the phase speed of the observed subannual Rossby waves is substantially slower than that expected from theory. Moreover, in the western part of the basin the phase speed of these waves is almost uniform between $30^{\circ}$ and $40^{\circ} \mathrm{N}$
(Fig. 8a). In addition, since on average the subannual waves are dominant across the entire basin in this zone, the phase speeds estimated from the total spectra are also almost uniform between $32^{\circ}$ and $40^{\circ} \mathrm{N}$ (Fig. 7b).

Last, analysis of the spatial structure reveals important differences in the nature of the observed waves to the east and west of the Mid-Atlantic Ridge. In the eastern part of the North Atlantic, Rossby waves radiate from the eastern boundary where an initial anomaly can be forced by large-scale processes, probably by a change in the large-scale wind or by large-scale topographic waves propagating along the eastern boundary. It appears that interaction with the Mid-Atlantic Ridge breaks the coherent structure of the waves but does not lead to their significant amplification, as suggested by earlier studies. Instead, a completely different structure for waves in the western part of the North Atlantic accompanied by larger energy results from what appears to be a source in the region to the southeast of the Grand Banks. Although beyond the scope of this study, we hypothesize that this source is related to temporal variability and/or structural changes of the Gulf Stream and the DWBC as they interact with the Newfoundland Ridge. For instance, substantial parts of these currents loop around the Grand Banks while some portion of each is thought to branch to the southeast towards the Mid-Atlantic Ridge. These processes create a large anomaly in oceanic properties oriented parallel to the axis of the Newfoundland Ridge, from the northwest to the southeast. [The hydrography of this region is poorly known; see Clark et al. (1980).] Rossby waves can radiate from this anomaly in a process of adjustment: excited Rossby waves try to smooth out the anomaly while the currents replenish the lost energy to sustain it. In reality, Gulf Stream path and strength vary in the vicinity of the Grand Banks, providing an additional time-dependent forcing of rich frequency content available for the resonant excitation of Rossby waves. Although the anomalies studied here have the spectral signature of Rossby waves, energy propagation in the wave field south of the Grand Banks is not consistent with that of simple linear Rossby waves.

Acknowledgments. This research was supported by NASA Grant NS033A06. We thank Dr. Nelson Hogg, Dr. Thomas Rossby, Dr. Lewis Rothstein, and Dr. Randolph Watts for their insightful comments on earlier versions of this paper.

\section{APPENDIX}

\section{Fitting of Dispersion Curve and Its Error Estimates}

Determination of the best-fit dispersion diagram was based on a nonlinear fit of the dispersion relation (1) to the estimated spectrum, with the Rossby radius of deformation $R_{d}$ being the unknown parameter. The merid- 
ional wavenumber $l$ was assumed to be zero, a reasonable assumption given that the observed wavelength was found to be an order of magnitude larger than the typical Rossby radius of deformation in the midlatitude range. For a given spectrum, a grid of dispersion curves (1) with $R_{d}$ ranging from 1 to $150 \mathrm{~km}$ in steps of $1 \mathrm{~km}$ was considered. For each curve within this grid, we averaged the spectral energy along the curve. The curve with the maximum average spectral energy was selected as the best-fit dispersion curve.

To evaluate the uncertainty of such an estimate, it is important to realize that each value of the optimal function, that is, the spectral energy averaged along a given dispersion curve, is simply an integrated spectrum. Thus, its uncertainty can be estimated similarly to that of a classical spectrum, that is, from a $\chi^{2}$ distribution with a certain number of degrees of freedom. The error bars for the position of the peak of the optimal function can be associated with those dispersion curves from the vicinity of the peak for which the optimal function is no less than the lower limit of the $95 \%$ confidence interval of the peak value.

To proceed, we need to determine the number of degrees of freedom $\nu$ involved in obtaining of the optimal function. This number results from multiplication of the number of spectral estimates $N$ along a particular dispersion curve by the number of degrees of freedom in evaluating the spectrum itself, $\nu_{\mathrm{PSD}}$. Thus, $\nu=N \nu_{\mathrm{PSD}}$. Since three time-longitude sections and averaging of three frequency/wavenumber bands were used to estimate each spectrum, $\nu_{\mathrm{PSD}}=2 \times 3 \times 3=18$, the same for all spectra. This means that the total number of degrees of freedom for a given value of the optimal function depends mostly on $N$, which in turn depends on the resolution of a given spectrum (here, the number of spectral points per unit length is important) and on how close a given dispersion curve is relative to the frequency or wavenumber axes (a number of dispersion curves that are too close to one of the axes pass through only a few spectral points or cannot be resolved in a given spectrum at all). Typically, $\nu$ was larger than 100 in the region between $15^{\circ}$ and $47^{\circ} \mathrm{N}$, and this resulted in relatively small uncertainties. North/south of this re- gion, most of the spectral energy was located too close to the frequency/wavenumber axis so that the lower/ upper confidence limit was zero/infinity.

\section{REFERENCES}

Chelton, D. B., and M. G. Schlax, 1996: Global observations of oceanic Rossby waves. Science, 272, 234-238.

—, R. A. de Szoeke, M. G. Schlax, K. El Naggar, and N. Siwertz, 1998: Geographical variability of the first baroclinic Rossby radius of deformation. J. Phys. Oceanogr., 28, 433-460.

Clarke, R. A., H. W. Hill, R. F. Reiniger, and B. A. Warren, 1980: Current system south and east of the Grand Banks of Newfoundland. J. Phys. Oceanogr., 10, 25-65.

Emery, W. J., and R. E. Thomson, 1998: Data Analysis Methods in Physical Oceanography. Pergamon, 634 pp.

Fu, L.-L., and D. B. Chelton, 2001: Large-scale ocean circulation. Satellite Altimetry and Earth Sciences, L.-L Fu and A. Cazenave, Eds., Academic Press, 133-169.

Gerdes, R., and C. Wübber, 1991: Seasonal variability of the North Atlantic Ocean-A model intercomparison. J. Phys. Oceanogr., 21, 1300-1322.

Hermann, P., and W. Krauss, 1989: Generation and propagation of annual Rossby waves in the North Atlantic. J. Phys. Oceanogr., 19, 727-744.

Jackson, L. B., 1996: Digital Filters and Signal Processing. Kluwer Academic, 502 pp.

Kamenkovich, I. V., and J. Pedlosky, 1998: Radiation of energy from nonzonal ocean currents, nonlinear regime. Part II: Interactions between waves. J. Phys. Oceanogr., 28, 1683-1701.

Lee, T., and P. Cornillon, 1996: Propagation and growth of Gulf Stream meanders between $75^{\circ}$ and $45^{\circ} \mathrm{W}$. J. Phys. Oceanogr., 26, 225-241.

Mann, C. R., 1967: The termination of the Gulf Stream and the beginning of the North Atlantic Current. Deep-Sea Res., 14, 337359.

Polito, P. S., and P. Cornillon, 1997: Long baroclinic Rossby waves detected by TOPEX/POSEIDON. J. Geophys. Res., 102, 32153235 .

Preisendorfer, R. W., 1988: Principal Component Analysis in Meteorology and Oceanography. Elsevier, $425 \mathrm{pp}$.

Schlax, M. G., and D. B. Chelton, 1994: Aliased tidal errors in TOPEX/POSEIDON sea surface height data. J. Geophys. Res., 99, 24 761-24 775.

Tokmakian, R. T., and P. G. Challenor, 1993: Observations in the Canary Basin and the Azores frontal region using Geosat data. J. Geophys. Res., 98, 4761-4773.

Van Snyder, W., and V. Zlotnicki, cited 2000: Sea surface height uniform latitude-longitude-time grids. [Available online at http://oceanesip.jpl.nasa.gov/sealevel/.]

Zang, X., and C. Wunsch, 1999: The observed dispersion relationship for North Pacific Rossby wave motions. J. Phys. Oceanogr., 29, 2183-2190. 